\title{
Management of post-cardiac arrest syndrome
}

\author{
Youngjoon Kang \\ Department of Emergency Medicine, Jeju National University Hospital, Jeju, Korea
}

Post-cardiac arrest syndrome is a complex and critical issue in resuscitated patients undergone cardiac arrest. Ischemic-reperfusion injury occurs in multiple organs due to the return of spontaneous circulation. Bundle of management practicies are required for post-cardiac arrest care. Early invasive coronary angiography should be considered to identify and treat coronary artery obstructive disease. Vasopressors such as norepinephrine and dobutamine are the first-line treatment for shock. Maintainance of oxyhemoglobin saturation greater than $94 \%$ but less than $100 \%$ is recommended to avoid fatality. Target temperature therapeutic hypothermia helps to resuscitated patients. Strict temperature control is required and is maintained with the help of cooling devices and monitoring the core temperature. Montorings include electrocardiogram, oxymetry, capnography, and electroencephalography (EEG) along with blood pressue, temprature, and vital signs. Seizure should be treated if EEG shows evidence of seizure or epileptiform activity. Clinical neurologic examination and magnetic resonance imaging are considered to predict neurological outcome. Glycemic control and metabolic management are favorable for a good neurological outcome. Recovery from acute kidney injury is essential for survival and a good neurological outcome.

Key Words: cardiopulmonary resuscitation; induced hypothermia; out-of-hospital cardiac arrest

\section{INTRODUCTION}

Cardiac arrest is a critical event and causes over 30,000 fatalities per year in South Korea [1]. Although the survival rate was $3.0 \%$ with a good neurological recovery rate of $0.9 \%$ from 2006 to 2010 in South Korea, the Korean Cardiac Arrest Research Consortium reported a survival rate of $11.5 \%$ with a good neurologic recovery (cerebral performance category [CPC] 1-2) rate of $7.8 \%$ from 2014 to 2015 [1,2].

Nolan et al. [3] proposed the term post-cardiac arrest syndrome, which was associated with (1) post-cardiac arrest brain injury, (2) post-cardiac arrest myocardial dysfunction, (3) systemic ischemia/reperfusion response, and (4) persistent precipitating pathology. Postcardiac arrest syndrome consist of five phases, which includes the immediate phase (20 minutes after the return of spontaneous circulation [ROSC]), early phase (from 20 minutes to 6-12 hours after ROSC), intermediate phase (from 6-12 to 72 hours after ROSC), recovery phase (3 days after ROSC), and rehabilitation phase.

During the post-cardiac arrest period, several systemic complications including acute respiratory distress syndrome, acute renal failure, refractory shock, and disseminated intravas-

\section{Review Article}

Received: August 20, 2019

Revised: August 23, 2019

Accepted: August 23, 2019

Corresponding author

Youngjoon Kang

Department of Emergency Medicine,

Jeju National University Hospital, 15

Aran 13-gil, Jeju 63241, Korea

Tel: +82-64-754-8106

E-mail: jedarm@jejunu.ac.kr

Copyright () 2019 The Korean Society of Critical Care Medicine

This is an Open Access article distributed under the terms of Creative Attributions Non-Commercial License (http:// creativecommons.org/li-censes/by-nc/4.0/) which permits unrestricted noncommercial use, distribution, and reproduction in any medium, provided the original work is properly cited. 
cular coagulation occurr and are associated with mortality [4]. Although the Korean rapid response system has helped reduce the rate of hospital mortality and in-hospital cardiac arrest after it has been introduced as an essential part of the medical system [5], systematic and proper management of post-cardiac arrest patients is important. This paper summarizes post-cardiac arrest care, including the newest update after 2015 American Heart Association Guidelines.

\section{PATHOPHYSIOLOGY AFTER RESUSCITATION}

Post-cardiac arrest syndrome is a combination of pathophysiological processes, which include (1) post-cardiac arrest brain injury, (2) post-cardiac arrest myocardial dysfunction, and (3) systemic ischemia/reperfusion response [6]. Although prolonged whole-body ischemia initially causes global tissue and organ injury, additional damage occurs during and after reperfusion [7,8]. The mechanism of brain injury includes altered calcium homeostasis, free radical formation, mitochondrial dysfunction, protease activation, and inflammation [9].

Along with the brain, another organ that expereicnes ischemic insult is the heart. Myocardial dysfunction is a common cause of early mortality after cardiac arrest and transient global dysfunction. which becomes apparent approximately 7 hours after ROSC and recovery within 48-72 hours [10]. Ischemia/reperfusion causes generalized activation of immunologic and coagulation pathways, which increase the risk of multiple organ failure and infection [9]. Clinical manifestations of ischemic-reperfusion injury include the depletion of intravascular volume, impaired vasoregulation, impaired oxygen delivery, and increased infection.

\section{HEMODYNAMIC AND CARDIAC MANAGEMENT}

\section{Coronary Angiography after Resuscitation}

Acute myocardial infraction is a common cause of cardiac arrest. Coronary angiography performed within 24 hours of admission is associated with a 2.3 -fold increase in good neurological outcome $(\mathrm{CPC} \leq 2)$ and survival at discharge $[11,12]$. Yao et al. [10] reported that 83 patients (44\%) had myocardial dysfunction and total of 37 patients (45\%) with myocardial dysfunction survived to discharge, $39 \%$ with intact neurologic status. Early myocardial dysfunction is not associated with neurologically intact survival. Chest pain complaint before arrest, ST segment elevation on ECG after ROSC, regional wall motion abnormality in echocardiography after resuscitation are more frequent in cardiac etiology group [13]. Patients suf-

\section{KEY MESSAGES}

- Management of post-cardiac arrest syndrome needs multimodality treatments of several systems.

- These include hemodynamic instability, myocardial dysfunction, coronary artery obstruction, airway and ventilator support, hypoxic-ischemic brain injury, targeted temperature therapeutic hypothermia, and prediction of neurologic outcome.

fering out-of-hospital cardiac arrest, those with old age, hypertension, positive cardiac enzyme, and initial shockable rhythm were associated with obstructive coronary artery disease. Early invasive coronary angiography should be considered in these patients [14].

\section{Echocardiography}

Echocardiography during resuscitation is suggested to be an important tool for the identification and treatment of reversible causes of death [13]. Post-resuscitation myocardial dysfunction occurs after ROSC. It is important to restore myocardial function to maintain blood pressure in the early post-cardiac arrest phase. Echocardiographic patterns of post-cardiac arrest left ventricle dysfunction include global hypokinesia, regional wall motion abnormalities, and Takotsubo pattern [15].

\section{Hemodynamic Monitoring}

Maintainance of systolic blood pressure greater than the fifth percentile for age is recommended with the use of parenteral fluid and/or inotropes or vasoactive drugs. Continuous arterial pressure monitoring is required to identify and treat hypotension.

\section{Antiarrhythmic and Inotropic Drugs}

There is insufficient evidence regarding the routine use of a $\beta$-blocker and lidocaine; however, the prophylactic use of lidocaine may be considered for recurrent ventricular fibrillation or ventricular tachycardia during transportation in the absence of contraindication. Avni et al. [16] recommended norepinephrine as the first-line vasopressor because norepinephrine was associated with decreased mortality, lower risk for major adverse events, and cardiac arrhythmias compared to dopamine. The combination norepinephrine-dobutamine is more effective and safer than epinephrine because epinephrine is associated with transient lactic acidosis, higher heart rate and arrhythmia, and inadequate gastric mucosa perfu- 
sion [17].

Sodium nitroprusside can be used for poor myocardial function by reducing afterload and an inotrope to improve contractility. Sodium nitroprusside-enhanced cardiopulmonary resuscitation improved ROSC and 4-hour survival in a porcine model of prolonged ischemic, refractory ventricular fibrillation cardiac arrest [18].

\section{AIRWAY AND VENTILATOR}

Elevated levels of $\mathrm{PO}_{2}$ contribute to oxidative stress that potentiates the post-cardiac arrest syndrome. Moreover, supranormal oxygen tension increases the risk of in-hospital mortality and decrease survival. However, there is some debate regading hyperoxia. Temporary hyperoxia following hypoxic insult showed no difference in inflammatory reaction compared with hypoxia-normoxia. On the contrary, temporary hyperoxia may suppress or minimize inflammation by the attenuation of Toll-like receptor 4. Therefore, continuous hyperoxygenation after successful cardiac arrest harms patients, but temporary hyperoxygenation with $100 \% \mathrm{O}_{2}$ in a clinical situation may prove helpful [19].

A $100 \mathrm{~mm} \mathrm{Hg}$ increase in partial pressure of oxygen $\left(\mathrm{PaO}_{2}\right)$ was associated with a $24 \%$ increase in mortality risk [20]. Mortality risk increased sharply with increasing hypoxia. Mortality risk was also associated with increasing hyperoxia although the association was not as significant as that with hypoxia [21]. Therefore, it is recommended to maintain an oxyhemoglobin saturation level of $94 \%-100 \%$. To achieve normoxemia, hypoxemia should be avoided by titrating oxygen appropriately.

Lee et al. [22] reported mean $\mathrm{PaO}_{2}$ had no independent association with in-hospital mortality, whereas hypocarbia was independently associated with in-hospital mortality. Del Castillo et al. [23] reported hypercapnia (odds ratio [OR], 3.27; 95\% confidence interval [CI], 1.62 to $6.61 ; \mathrm{P}=0.001$ ) and hypocapnia (OR, 2.71; 95\% CI, 1.04 to $7.05 ; \mathrm{P}=0.04$ ) after ROSC were associated with high mortality. It is recommended to avoid severe hypercapnia or hypocapnia and monitor end-tidal $\mathrm{CO}_{2}$.

Pneumonia is the common cause of infection associated with post-cardiac arrest syndrome. However, prophylactic antibiotic therapy during hypothermia treatment in post-cardiac arrest patients cannot reduce the incidence of early-onset pneumonia [24]. Additionally, it does not affect the duration of mechanical ventilation, the length of ICU stay, in-hospital mortality, and poor neurological outcome [25].

\section{NEUROLOGIC SYSTEM AND MANAGEMENT}

\section{Target Temperature Therapeutic Hypothermia}

Targeted temperature management (TTM) is well known to benefit patients resuscitated from cardiac arrest. Kim et al. [26] found that TTM was related to a three-fold increase in neurologically favorable survival with TTM treatment in the initial non-shockable rhythm.

Time to target temperature was shorter and deviation from the maintenance temperature occurred less frequently using gel pad cooling device management. The gel pad cooling device is superior to the water blanket for strict temperature control during TTM [27]. The maximum target temperature should not exceed $36^{\circ} \mathrm{C}$.

\section{Monitoring}

Intensive monitoring is needed for investigating organ dysfunction after ROSC. Monitoring includes elective cardiogram, pulse oximetry, capnography, blood pressure, temperature, and urine output. An arterial catheter should be placed for the identification and treatment of hypotension and a central venous catheter is useful for monitoring central venous oxygen saturation and fluid and medication administration. A bladder temperature catheter or esophageal probe will be used for monitoring the core body temperature.

Early electroencephalography (EEG) can predict neurological outcome. A suppressed and featureless EEG background is associated with a poor neurological outcome and electrographic seizures are associated with a good neurological outcome [28]. S-100B protein levels peaked at ROSC (0 hour), decreased rapidly to 6 hours, and maintained a similar level thereafter; therefore, it is a useful marker for predicting poor neurological outcome in post-cardiac arrest syndrome. The optimal sampling times of S-100B protein were 24 and 36 hours after ROSC [29].

Cerebral blood flow is low after cardiac arrest, and postanoxic encephalopathy-contributed autoregulation, loss of normal vascular tone, and increased cerebral blood flow may contribute to secondary brain damage and lead to fatal brain injury [30]. The incidence of seizures after cardiac arrest is about $8 \%-23 \%$, and the presence of epileptiform activity or interictal epileptiform discharges are associated with a poor neurological outcome or death $[31,32]$. Although prophylactic anticonvulsant use is not beneficial, seizures should be treated with benzodiazepines and anticonvulsant drugs. The electroencephalogram should be monitored in resuscitated patients with a comatose mentality. Continuous EEG monitor- 
ing provides dynamic information and can be used to assess the evolution of EEG patterns and detect seizures [33].

\section{Predicting Neurological Outcome}

Cerebral ischemia after cardiac arrest provokes morbidity and mortality through ischemic-reperfusion injury and organ failure. There are several parameters which predict the good neurological outcome of resuscitated patients. Cerebral oximetry measures regional cerebral oxygen saturation in the frontal lobe using near infra-red spectroscopy. Brain magnetic resonance imaging shows hypoxic-ischemic encephalopathy and neurologic sequelae include memory disturbance, amnesia, insomnia, and visual deficit.

Pupillary light reflex at $\geq 72$ hours and corneal reflex at 72 hours likely indicate a poor outcome in patients. Myoclonus, short-latency somatosensory evoked potentials, neuron-specific enolase, and S-100B are also predictors of neurological outcome. Diffusion-weighted magnetic resonance images are taken 2-5 days after ROSC, and hypoxic ischemic brain injury includes the occipital cortex, deep grey nuclei, hippocampus, and cerebellum [34].

\section{METABOLIC MANAGEMENT}

Ammonia and lactate levels were higher and $\mathrm{pH}$ levels were lower in the poor outcome group [28]. Shida et al. [35] reported that high serum potassium level was significantly and dosedependently associated with poor neurological outcomes. The highest proportion of favorable neurological outcome was $44.8 \%$ in Q1 group ( $\mathrm{K} \leq 3.8 \mathrm{mEq} / \mathrm{L})$, and the proportion of favorable neurological outcomes decreased as the serum potassium level increased. Therefore, serum potassium on hospital arrival may be an effective prognostic indicator for outof-hospital cardiac arrest achieving ROSC.

Hyperglycemia and hypoglycemia are associated with poor neurological outcome, but no target range of glucose management is indicated in resuscitated patients from cardiac arrest. Blood glucose values up to $8.0 \mathrm{mmol} / \mathrm{L}$ are acceptable for out-of-hospital cardiac arrest patients treated with therapeutic hypothermia because a more strict approach seems not to offer additional mortality reduction, but instead may expose patients to the detrimental effects of hypoglycemia [36].

\section{Renal System}

Acute kidney injury (AKI) is serious problem and occurs in almost half of all patients after cardiac arrest. AKI contributes to inflammatory injury in the hippocampus and altered blood- brain barrier permeability; therefore, after cardiac arrest, patients with AKI had more severe hemodynamic impairment and needed aggressive ICU therapy. Age, epinephrine dose, cumulative fluid balance, and presence of shock were independent predictors of AKI development [37]. Recovery from AKI is a potent predictor of survival and good neurological outcome at discharge after out-of-hospital cardiac arrest [38].

Decreased urine output $(<1 \mathrm{ml} / \mathrm{kg} / \mathrm{hr}$ in infants and children or $<30 \mathrm{ml} / \mathrm{hr}$ in adolescents) may be caused by prerenal conditions (e.g., dehydration, inadequate systemic perfusion), renal ischemic damage, or a combination of the aforementioned factors. Avoidance of nephrotoxic medications and adjustment of the dose of medications excreted by the kidneys are recommended until renal function has been checked.

\section{CONCLUSIONS}

Although basic life support has been widely practiced to increase recovery from cardiac arrest, management of post-cardiac arrest patients have also made great progress. Management of post-cardiac arrest syndrome patients includes complex and multidisciplinary interventions. Early and intensive management should be focused on hemodynamic stability and neurologic recovery.

\section{CONFLICT OF INTEREST}

No potential conflict of interest relevant to this article was reported.

\section{ORCID}

Youngjoon Kang https://orcid.org/0000-0002-3550-7755

\section{REFERENCES}

1. Kim JY, Hwang SO, Shin SD, Yang HJ, Chung SP, Lee SW, et al. Korean Cardiac Arrest Research Consortium (KoCARC): rationale, development, and implementation. Clin Exp Emerg Med 2018;5:165-76.

2. Ro YS, Shin SD, Song KJ, Lee EJ, Kim JY, Ahn KO, et al. A trend in epidemiology and outcomes of out-of-hospital cardiac arrest by urbanization level: a nationwide observational study from 2006 to 2010 in South Korea. Resuscitation 2013;84:54757.

3. Nolan JP, Neumar RW, Adrie C, Aibiki M, Berg RA, Böttiger BW, et al. Post-cardiac arrest syndrome: epidemiology, patho- 
physiology, treatment, and prognostication. A scientific statement from the International Liaison Committee on Resuscitation; the American Heart Association Emergency Cardiovascular Care Committee; the Council on Cardiovascular Surgery and Anesthesia; the Council on Cardiopulmonary, Perioperative, and Critical Care; the Council on Clinical Cardiology; the Council on Stroke. Resuscitation 2008;79:350-79.

4. Kim JH, Oh YM, So BH, Hong TY, Lee WJ, Choi SP, et al. Systemic complications of comatose survivors following cardiopulmonary resuscitation. J Korean Soc Emerg Med 2008;19: 88-93.

5. Lee BY, Hong SB. Rapid response systems in Korea. Acute Crit Care 2019;34:108-16.

6. Neumar RW, Nolan JP, Adrie C, Aibiki M, Berg RA, Böttiger BW, et al. Post-cardiac arrest syndrome: epidemiology, pathophysiology, treatment, and prognostication. A consensus statement from the International Liaison Committee on Resuscitation (American Heart Association, Australian and New Zealand Council on Resuscitation, European Resuscitation Council, Heart and Stroke Foundation of Canada, InterAmerican Heart Foundation, Resuscitation Council of Asia, and the Resuscitation Council of Southern Africa); the American Heart Association Emergency Cardiovascular Care Committee; the Council on Cardiovascular Surgery and Anesthesia; the Council on Cardiopulmonary, Perioperative, and Critical Care; the Council on Clinical Cardiology; and the Stroke Council. Circulation 2008;118:2452-83.

7. Opie LH. Reperfusion injury and its pharmacologic modification. Circulation 1989;80:1049-62.

8. White BC, Grossman LI, Krause GS. Brain injury by global ischemia and reperfusion: a theoretical perspective on membrane damage and repair. Neurology 1993;43:1656-65.

9. Neumar RW. Molecular mechanisms of ischemic neuronal injury. Ann Emerg Med 2000;36:483-506.

10. Yao Y, Johnson NJ, Perman SM, Ramjee V, Grossestreuer AV, Gaieski DF. Myocardial dysfunction after out-of-hospital cardiac arrest: predictors and prognostic implications. Intern Emerg Med 2018;13:765-72.

11. Shin J, Ko E, Cha WC, Lee TR, Yoon H, Hwang SY, et al. Impact of early coronary angiography on the survival to discharge after out-of-hospital cardiac arrest. Clin Exp Emerg Med 2017; 4:65-72.

12. Park JK, Na SH, Kim TH, Shin SD, Song KJ, Ro YS, et al. Association of coronary angiography and percutaneous coronary intervention to survival outcome of patients successfully resuscitated from out-of-hospital cardiac arrest. J Korean Soc Emerg Med 2016;27:540-8.
13. Kang HS, Lee HJ, Cho JH, Paik JH, Kim JH, Kim JS, et al. Outcome after admission to intensive care unit following out-ofhospital cardiac arrest: comparison between cardiac etiology and non-cardiac etiology. Korean J Crit Care Med 2010;25: 212-8.

14. Park J, Shin J, Kim HL, Song KJ, Jung JH, Lee HJ, et al. Clinical factors associated with obstructive coronary artery disease in patients with out-of-hospital cardiac arrest: data from the Korean Cardiac Arrest Research Consortium (KoCARC) Registry. J Korean Med Sci 2019;34:e159.

15. Cha KC, Kim HI, Kim OH, Cha YS, Kim H, Lee KH, et al. Echocardiographic patterns of postresuscitation myocardial dysfunction. Resuscitation 2018;124:90-5.

16. Avni T, Lador A, Lev S, Leibovici L, Paul M, Grossman A. Vasopressors for the treatment of septic shock: systematic review and meta-analysis. PLoS One 2015;10:e0129305.

17. Levy B, Perez P, Perny J, Thivilier C, Gerard A. Comparison of norepinephrine-dobutamine to epinephrine for hemodynamics, lactate metabolism, and organ function variables in cardiogenic shock: a prospective, randomized pilot study. Crit Care Med 2011;39:450-5.

18. Yannopoulos D, Bartos JA, George SA, Sideris G, Voicu S, Oestreich B, et al. Sodium nitroprusside enhanced cardiopulmonary resuscitation improves short term survival in a porcine model of ischemic refractory ventricular fibrillation. Resuscitation 2017;110:6-11.

19. Cho YD, Park SJ, Choi SH, Yoon YH, Kim JY, Lee SW, et al. The inflammatory response of neutrophils in an in vitro model that approximates the postcardiac arrest state. Ann Surg Treat Res 2017;93:217-24.

20. Kilgannon JH, Jones AE, Parrillo JE, Dellinger RP, Milcarek B, Hunter K, et al. Relationship between supranormal oxygen tension and outcome after resuscitation from cardiac arrest. Circulation 2011;123:2717-22.

21. Ferguson LP, Durward A, Tibby SM. Relationship between arterial partial oxygen pressure after resuscitation from cardiac arrest and mortality in children. Circulation 2012;126:335-42.

22. Lee BK, Jeung KW, Lee HY, Lee SJ, Jung YH, Lee WK, et al. Association between mean arterial blood gas tension and outcome in cardiac arrest patients treated with therapeutic hypothermia. Am J Emerg Med 2014;32:55-60.

23. Del Castillo J, López-Herce J, Matamoros M, Cañadas S, Rodriguez-Calvo A, Cechetti C, et al. Hyperoxia, hypocapnia and hypercapnia as outcome factors after cardiac arrest in children. Resuscitation 2012;83:1456-61.

24. Kim SJ, Lee JK, Kim DK, Shin JH, Hong KJ, Heo EY. Effect of antibiotic prophylaxis on early-onset pneumonia in cardiac 
arrest patients treated with therapeutic hypothermia. Korean J Crit Care Med 2016;31:17-24.

25. Kakavas S, Mongardon N, Cariou A, Gulati A, Xanthos T. Early-onset pneumonia after out-of-hospital cardiac arrest. J Infect 2015;70:553-62.

26. Kim SG, Cha WC, Sim MS, Hwang SY, Shin TG, Park JH, et al. Targeted temperature management is related to improved clinical outcome of out-of-hospital cardiac arrest with nonshockable initial rhythm. J Korean Soc Emerg Med 2019;30: 208-16.

27. Jung YS, Kim KS, Suh GJ, Cho JH. Comparison between gel pad cooling device and water blanket during target temperature management in cardiac arrest patients. Acute Crit Care 2018;33:246-51.

28. Yang DH, Ha SG, Kim HJ. EEG can predict neurologic outcome in children resuscitated from cardiac arrest. J Korean Child Neurol Soc 2018;26:240-5.

29. Kim HS, Jung HS, Lim YS, Woo JH, Jang JH, Jang JY, et al. Prognostic value and optimal sampling time of S-100B protein for outcome prediction in cardiac arrest patients treated with therapeutic hypothermia. Korean J Crit Care Med 2014;29: 304-12.

30. van den Brule JM, van der Hoeven JG, Hoedemaekers CW. Cerebral perfusion and cerebral autoregulation after cardiac arrest. Biomed Res Int 2018;2018:4143636.

31. Mani R, Schmitt SE, Mazer M, Putt ME, Gaieski DF. The frequency and timing of epileptiform activity on continuous electroencephalogram in comatose post-cardiac arrest syndrome patients treated with therapeutic hypothermia. Resuscitation 2012;83:840-7.

32. Towne AR, Waterhouse EJ, Boggs JG, Garnett LK, Brown AJ, Smith JR Jr, et al. Prevalence of nonconvulsive status epilepticus in comatose patients. Neurology 2000;54:340-5.

33. Friberg H, Westhall E, Rosén I, Rundgren M, Nielsen N, Cronberg T. Clinical review: continuous and simplified electroencephalography to monitor brain recovery after cardiac arrest. Crit Care 2013;17:233.

34. Sandroni C, D’Arrigo S, Nolan JP. Prognostication after cardiac arrest. Crit Care 2018;22:150.

35. Shida H, Matsuyama T, Iwami T, Okabayashi S, Yamada T, Hayakawa K, et al. Serum potassium level on hospital arrival and survival after out-of-hospital cardiac arrest: The CRITICAL study in Osaka, Japan. Eur Heart J Acute Cardiovasc Care 2019:2048872619848883.

36. Oksanen T, Skrifvars MB, Varpula T, Kuitunen A, Pettilä V, Nurmi J, et al. Strict versus moderate glucose control after resuscitation from ventricular fibrillation. Intensive Care Med 2007;33:2093-100.

37. Tujjar O, Mineo G, Dell'Anna A, Poyatos-Robles B, Donadello $\mathrm{K}$, Scolletta S, et al. Acute kidney injury after cardiac arrest. Crit Care 2015;19:169.

38. Park YS, Choi YH, Oh JH, Cho IS, Cha KC, Choi BS, et al. Recovery from acute kidney injury as a potent predictor of survival and good neurological outcome at discharge after outof-hospital cardiac arrest. Crit Care 2019;23:256. 